\title{
Light-Induced Changes in an Aqueous $\beta$-Carotene System Stored under Halogen and Fluorescent Lamps, Affected by Two Oxygen Partial Pressures
}

\author{
Sara Limbo,* Luisa Torri, and Luciano Piergiovanni \\ Department of Food Science and Microbiology, University of Milan, Via Celoria 2, \\ 20133 Milan, Italy
}

\begin{abstract}
The aim of this work was to investigate the reaction kinetics of $\beta$-carotene in an aqueous medium as a function of exposure to commercial lights (halogen and fluorescent sources) and oxygen partial pressures. The evolution of the pigment concentration, the changes in color, and the accumulation of a volatile compound ( $\beta$-ionone) were monitored during storage. The kinetics of degradation were mathematically modeled to compare the effects of lighting conditions and oxygen partial pressures. Lighting was also a critical variable in the presence of a low oxygen partial pressure $(5 \mathrm{kPa})$, and in these conditions, the $\beta$-carotene degraded completely during storage, even if more slowly than at 20 $\mathrm{kPa}$ of $\mathrm{O}_{2}$. The pigment degradation was correlated to illuminance and UVA irradiance values, but the different decay rates of the fluorescent lamps were explained by the differences in the blue region of the energy emission spectra. A halogen lamp gave minor negative effects on $\beta$-carotene degradation.
\end{abstract}

KEYWORDS: Light; halogen lamp; fluorescent lamp; $\beta$-carotene; $\beta$-ionone; aqueous system; color

\section{INTRODUCTION}

Food color and appearance are important visually perceived factors that contribute to customer selection (l). To fulfill the consumer's desire to visually appraise the product and to convince the potential buyer about the quality of the food prior to the purchase, transparent packaging materials are often used $(2-5)$. During distribution and at the retail level, the clear packages are exposed to natural and artificial light, which may deteriorate the food quality and marketability, depending on the photosensitivity of the product. Moreover, cut, sliced, or grated foods are more susceptible to light-induced damage since they expose a larger surface area to light $(4,5)$. In food and beverages, photochemical degradation occurs almost exclusively on the surface since level light penetration is very low, in particular when the products have a compact texture (6). In fact, the matrix influences the penetration level of light and, therefore, the rate of light-induced reactions. Generally, the scattering intensity of light at wavelength $\lambda$ by a particle of diameter $r$ is proportional to $r^{6} / \lambda^{4}$ and increases with a higher number of particles $(5,7)$.

In general, light exposure causes the deterioration of lipids, vitamins, proteins, and natural pigments, which results in offflavors, loss of flavor and nutrients, and color fading $(3,8)$. The most harmful wavelengths are usually in the ultraviolet part of the spectrum, just below the visible range. This is due to the high-energy content, which is capable of splitting certain

* To whom correspondence should be addressed. Tel: +3902 50316659. Fax: +3902 50316672. E-mail: sara.limbo@unimi.it. chemical bonds $(6,9)$. The effects of light on the degradation of packaged foods have been widely investigated especially when lipidic substrates are involved (10); attention has therefore been focused on fatty foods, which contain pigments (milk, cheese, butter, yogurt, meat and meat products, oils, etc.) $(5$, $11,12)$. The effect of light on the lipid oxidation and flavor stability may be attributed to photolytic free radical autoxidation and/or photosensitized oxidation $(5,13,14)$. Photolytic free radical autoxidation is the production of free radicals, primarily from lipids, during exposure to far-UV and high-energy light, with intensities such as 10000-100000 lux $(5,14,15)$. In the same way, light in the wavelength range of the visible spectrum might cause considerable problems, especially when the product contains photosensitizer molecules such as chlorophylls, carotenoids, flavonoids, anthocyanins, betaines, etc. These components, in fact, are characterized by their conjugated double-bond system. When light energy is absorbed, the sensitizer is converted into a triplet excited state, which can interact easily with another molecule, producing free radicals, or with molecular oxygen, leading to the formation of highly reactive singlet oxygen. The reaction rate of singlet oxygen with some food components is much greater than that of triplet oxygen: In fact, singlet oxygen can attack double bonds directly; for example, its reactivity with linoleic acid is about 1450 times faster than that of ground triplet state oxygen (13).

Photodegradative reactions might also take place in aqueous systems that do not contain fats but photosensitizer compounds such as natural pigments or artificial colorants (16-19). Among the numerous compounds available to the food industry, the 
pigments belonging to the carotenoids group are widely used for coloring foods and beverages and also for increasing their nutrient stability. In fact, the increased awareness of healthy eating has led the consumer to prefer foods with a high nutritional value. For these reasons, natural substances are often added to many foods to make them healthier and more appealing. In particular, $\beta$-carotene has drawn considerable attention because of its role as an antioxidant that could reduce the risk of certain types of cancer and cardiovascular diseases. $\beta$-Carotene is a critical substance because it can act as pro/ antioxidant as a function of some variables and it is sensitive to $\mathrm{pH}$, temperature, and oxygen. Light also plays an important role in $\beta$-carotene degradation because it is a photosensitive molecule, although many foods and beverages that contain $\beta$-carotene are sold in stores where artificial light is used for illumination. In this case, not much information is available on the specific effects of light, whereas the effects of temperature are frequently studied $(10,16,18)$. Generally, food photosensitivity is influenced by a number of factors: concentration of oxygen in the head space of the pack and dissolved in the product, oxygen permeability of the packaging material, storage temperature, exposure time to light, distance between the product and the light source, spectral emission and intensity light, transmittance level of packaging material, reflectance, transmittance, and absorbance spectra of the food product (5). For these reasons, not only the processing parameters but also the packaging materials and storage conditions must be selected and controlled to reduce degradation. A large number of works are focused on the effects of monochromatic lights (20-23), but only few evaluate the exposure under real light sources (14, $24-26$ ). For this reason, the aim of this work was to investigate the effects of various typologies of lamps used by different commercial retail stores to illuminate food products on carotenoids. In this way, the reaction kinetics of $\beta$-carotene in an aqueous medium as a function of exposure to commercial light sources with different spectral emission were studied. In these conditions, the effects of two different oxygen partial pressures were also investigated.

\section{MATERIALS AND METHODS}

Samples Preparation. A water dispersible $\beta$-carotene powder (Roha Caleb Ltd., United Kingdom) was used to prepare an aqueous solution at a concentration of $18 \mu \mathrm{g} \mathrm{mL}{ }^{-1}$. The powder consisted of $\beta$-carotene $(10 \% \mathrm{w} / \mathrm{w})$ solubilized in genetically modified free vegetable oil embedded in the form of very fine droplets coated with a matrix composed of dextrin and glucose (particle size: minimum, $98 \%$ smaller than $200 \mu \mathrm{m}$; maximum, $8 \%$ smaller than $50 \mu \mathrm{m}$ ). The powder contained calcium phosphate (E341) as an anticaking agent that assured the stability of the fine emulsion during the experimental time. In fact, suspended particles were never visible in samples, and the opacity (measured as absorbance at $660 \mathrm{~nm})(27,28)$ did not increase over 10 days of storage.

The solution was buffered at $\mathrm{pH} 7.2$ with citric acid $-\mathrm{Na}_{2} \mathrm{HPO}_{4}$, and $0.5 \mathrm{~mL}$ of ethanol $(98 \% \mathrm{v} / \mathrm{v})$ was added to prevent microbial growth during storage. The samples were composed of $10 \mathrm{~mL}$ of solution contained in $22 \mathrm{~mL}$ glass vials (clear in the UV-vis region of the spectrum) inside of which two oxygen partial pressures were created. A set of vials was hermetically closed under $20.9 \mathrm{kPa}$ of oxygen to simulate packaging in air, while another set was conditioned under 5 $\mathrm{kPa}$ of oxygen using an automatic packaging machine (Tecnovac S100 DGT gas) connected to a gas mixer (PBI Dansensor MAP mix 9000) to simulate oxygen residual after modified atmosphere packaging. The vials were then hermetically closed with PTFE/butyl septa and aluminum crimp tops.

Storage Experiment and Light Exposure. Each set of vials was stored horizontally on black turning plates inside thermostated and
Table 1. Technical Characteristics of the Lamps Used for Lighting Samples

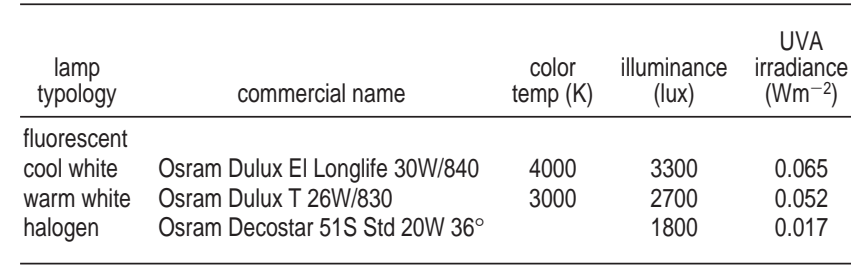

ventilated cabinets for 11 days at $33 \pm 2{ }^{\circ} \mathrm{C}$. Data loggers (Smart Reader SR04) were used to verify the real temperature. During storage, the samples were exposed to constant illumination produced by different light sources, and the same number of samples were also conditioned in the darkness. The lamps and the conditions of lighting used in the storage experiments were selected after a census in different largescale retail stores in Milan and on the outskirts of the city. Details of this part of the experiment are reported elsewhere (29). In particular, a cool white lamp (Osram Dulux El Longlife 30W/840), a warm white lamp (Osram Dulux T 26W/830), and a halogen lamp (Osram Decostar 51S Standard 20W $36^{\circ}$ ) were used. The lamps were installed inside the cabinets and placed $18 \mathrm{~cm}$ above the samples. To avoid lightreflecting phenomena, the internal walls of the cabinets were tinted black. For each selected light, illuminance and irradiance in the visible and UVA regions were measured under real storage conditions at the level of the samples (Table 1).

Determination of $\boldsymbol{\beta}$-Carotene Concentration and Color Evolution of the Solutions. Samples were withdrawn in triplicate for analysis at predetermined times. The pigment degradation was controlled by monitoring the residual $\beta$-carotene and the color change.

The amount of $\beta$-carotene was determined by measuring absorbance at the $\lambda_{\max }(479 \mathrm{~nm})$ using an UV-visible spectrophotometer (PerkinElmer Lambda 650). This method of monitoring carotene oxidation is well-established and has been used previously in many studies (30, $31)$. From a stock solution of $\beta$-carotene, 13 standard solutions were prepared by successive dilution with concentrations ranging from 1 to $22 \mu \mathrm{g} \mathrm{mL}^{-1}$. To construct the calibration curve, all of the standard solutions were prepared and analyzed in triplicate. The evolution of the color of the samples was monitored by means of the CIE $L^{*} a^{*} b^{*}$ parameters calculated by the software Color version 3.00 (Perkin-Elmer Instruments) from the transmittance spectrum acquired in the visible region $(380-780 \mathrm{~nm})$.

Isolation and Determination of $\boldsymbol{\beta}$-Ionone. The production of a volatile compound ( $\beta$-ionone) by means of the headspace solid-phase microextraction (HS-SPME) technique was evaluated. The SPME device was from Supelco Co. (Bellefonte, PA). Prior to the sample headspace exposure, the $10 \mathrm{~mm}$ fiber coated with $100 \mu \mathrm{m}$ polydimethylsiloxane was thermally conditioned by its insertion into the gas chromatography (GC) injector port at $250{ }^{\circ} \mathrm{C}$ for $30 \mathrm{~min}$, as recommended by the manufacturer. Moreover, each day, the fiber was activated by inserting it into the $\mathrm{GC}$ injector at $250{ }^{\circ} \mathrm{C}$ for $20 \mathrm{~min}$.

For each extraction, the vial containing $10 \mathrm{~mL}$ of $\beta$-carotene aqueous solution was thermostated for $3 \mathrm{~min}$ at $50{ }^{\circ} \mathrm{C}$ in a water bath, submerging it only as far as necessary to submerge the liquid phase of the sample to help keep the SPME fiber cool. Then, the fiber was manually inserted into the sample vial at the above-mentioned temperature for an adsorption time of $30 \mathrm{~min}$.

The volatile compounds extracted by HS-SPME procedure were identified using a gas chromatograph coupled to a mass selective detector. In particular, the GC instrument (model Autosystem XL, Perkin-Elmer Inc., United States) was equipped with a polar capillary column (SupelcowaxTM-10 $30 \mathrm{~m} \times 0.25 \mathrm{~mm}$ i.d. $\times 0.25 \mu \mathrm{m}$ film thickness). Helium was used as the carrier gas at a flow rate of $1 \mathrm{~mL} /$ min. The volatile compounds were desorbed in the GC injector in splitless mode at $250{ }^{\circ} \mathrm{C}$ for $2 \mathrm{~min}$ (preliminary studies indicated that this exposure time permitted the fiber to be clean). The injector and transfer line temperatures were 250 and $280{ }^{\circ} \mathrm{C}$, respectively, and the oven temperature program was as follows: $40{ }^{\circ} \mathrm{C}$ increased to $150{ }^{\circ} \mathrm{C}$ at $10{ }^{\circ} \mathrm{C} / \mathrm{min}$ and to $190{ }^{\circ} \mathrm{C}$ at $5^{\circ} \mathrm{C} / \mathrm{min}$. 

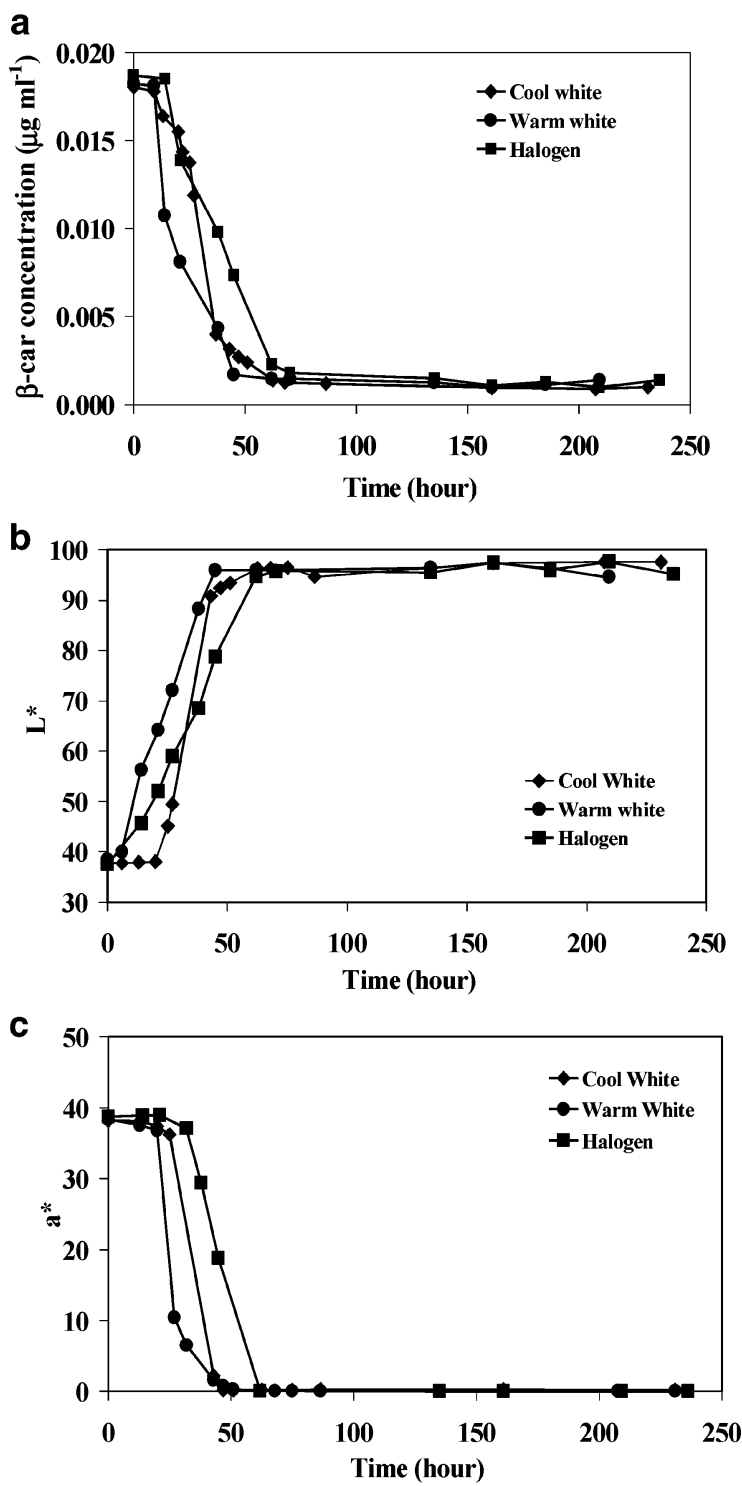

Figure 1. Sigmoid shape of some $\beta$-carotene concentration (a), $L^{*}(\mathbf{b})$, and $a^{*}$ (c) curves during storage at $20 \mathrm{kPa}$ of oxygen.

The quadrupole mass detector (model Turbo Mass, Perkin-Elmer Inc.) was operated in the electron ionization mode at a voltage of 70 $\mathrm{eV}$. The ion source temperature was set at $180^{\circ} \mathrm{C}$. The electron impact spectra were recorded at $1 \mathrm{~s} / \mathrm{scan}$ in the mass range of $40-620 \mathrm{~m} / \mathrm{z}$. The peak of $\beta$-ionone was identified via a comparison with the NIST mass spectral library (version $1.7,1999)$ and the retention time of the chemical standard ( $\geq 95.0 \%$ Fluka, Switzerland).

\section{RESULTS AND DISCUSSION}

The effects of three selected lamps (cool white, warm white, and halogen) on the stability of $\beta$-carotene were performed by monitoring its concentration and color changes during time. It was evident that the changes in the $\beta$-carotene concentration and also those in the $L^{*}$ and $a^{*}$ CIE parameters had a sigmoid shape, as shown in Figure 1 for the storage at $20 \mathrm{kPa}$ of oxygen. An induction time was evident, and the decay rate did not decline immediately but decreased up to a minimum before steadily reaching an asymptotic level (Figure 1a).

The same trend was obtained for the evolution of the color coordinate $a^{*}$, as it can be seen in Figure 1c referred to the 20 $\mathrm{kPa}$ of oxygen. The $L^{*}$ values (Figure 1b), after the induction time, increased up to a maximum before reaching the asymptotic level. A different behavior was observed for the $b^{*}$ values (data not shown): In fact, in all of the lighting experiments, the induction phase was not evident and a maximum was observed after a few hours from storage and before its decrease up to a constant value. For this reason, the $b^{*}$ data will not be discussed in this paper.

From a literature review, it has been noted that the degradation of this carotenoid follows different order kinetic models, as a function of the type of $\beta$-carotene, the substrate compound involved, and, also, the lighting conditions. For example, JarénGalàn and Minguez-Mosquera (32) reported that $\beta$-carotene degradation during time in phosphate buffer under an illuminance of 1000 lux was fitted by a first-order kinetic model; however, in this work, the authors gave no information about the typology of the lamp and the conditions of expositions. On the other hand, Gao and co-worker (33) observed a zero-order kinetic for $\beta$-carotene in dichloromethane solution when irradiated with near-UV and visible light. These last findings were in agreement with the conclusions indicated in other papers about the effect of ozone, oxygen exposures, and heat treatment on carotenoid degradation in an aqueous medium $(16,18)$. Even if the substrate used in these experiments was the same as ours (i.e., water), the experiments were carried out without considering the light exposition. The sigmoid pattern has been noticed in the literature where many decay data have been described by a number of so-called sigmoid models, such as the Logistic, Gompertz, Richards Morgan, and Weibull models (34-36). In particular, the sigmoid trend was also found both in the degradation of color pigments (mostly carotenoids) in dehydrated and ground chili peppers during 12 months of storage (37) and in the overall degradation pattern of the vitamin A palmitate-only sample at ambient temperature (38).

In this work, the Gompertz model as modified by Zwietering et al. (39) (eq 1), adapted to both growth and decay kinetics, was chosen to describe the sigmoid behavior of the $\beta$-carotene concentration and the $L^{*}$ and $a^{*}$ changes, to obtain information that made it possible to compare the effects of both light exposure and oxygen partial pressure.

$$
\begin{array}{r}
\log \left(C / C_{0}\right)= \pm A \times \exp \{-\exp \{[(\mu \times 2.7182) \times \\
\left.\left.\left.\frac{\lambda-t}{A}\right]+1\right\}\right\}
\end{array}
$$

where $C$ is the $\beta$-carotene concentration (or $L^{*}$ and $a^{*}$ value) at time $t, C_{0}$ is the $\beta$-carotene concentration (or $L^{*}$ and $a^{*}$ ) value at time $0, A$ is the increase (or decrease) in $\log C / C_{0}$ between the maximum and the minimum value achieved at the stationary phase and time $0, \mu$ is the maximal increase or decrease rate $\left[\Delta \log \left(C / C_{0}\right) / \mathrm{h}\right], \lambda$ is the induction time $(\mathrm{h})$, and $t$ is the time (h).

Table Curve 2D Software Version 4 (Jandel Scientific Software) was used for the nonlinear regression analysis and to determine the parameters of the modified Gompertz equation.

The goodness of fit of the experimental data was evaluated by means of the adjusted $R^{2}$ and the root-mean-square error (RMSE, eq 2), which measures the average deviation between the observed and the fitted values. The small RMSE value indicates a better fit of data for that model (40)

$$
\mathrm{RMSE}=\sqrt{\sum \frac{(\text { fitted }- \text { observed })^{2}}{n-p}}
$$

where $n$ is the number of observations and $p$ is the number of parameters to be estimated. The results are shown in Table 2. 
Table 2. $R^{2}$ and RMSE Values of the Data Fitting for All Tested Conditions

\begin{tabular}{|c|c|c|c|c|c|c|}
\hline \multirow[b]{2}{*}{$\begin{array}{c}\text { oxygen } \\
(\mathrm{kPa})\end{array}$} & \multicolumn{2}{|c|}{$\beta$-carotene concentration } & \multicolumn{2}{|c|}{$L^{*}$} & \multicolumn{2}{|c|}{$a^{*}$} \\
\hline & $R^{2}$ & RMSE & $R^{2}$ & RMSE & $R^{2}$ & RMSE \\
\hline \multicolumn{7}{|c|}{ dark } \\
\hline $\begin{array}{r}20 \\
5\end{array}$ & $\begin{array}{l}0.988 \\
0.989\end{array}$ & $\begin{array}{l}0.028 \\
0.021\end{array}$ & $\begin{array}{l}0.998 \\
0.979\end{array}$ & $\begin{array}{l}0.013 \\
0.023\end{array}$ & $\begin{array}{l}0.994 \\
0.989\end{array}$ & $\begin{array}{l}0.023 \\
0.076\end{array}$ \\
\hline \multicolumn{7}{|c|}{ cool white } \\
\hline 20 & 0.993 & 0.045 & 0.999 & 0.004 & 0.994 & 0.099 \\
\hline 5 & 0.997 & 0.030 & 0.981 & 0.025 & 0.997 & 0.044 \\
\hline \multicolumn{7}{|c|}{ warm white } \\
\hline 20 & 0.989 & 0.028 & 0.994 & 0.012 & 0.971 & 0.251 \\
\hline 5 & 0.997 & 0.030 & 0.975 & 0.331 & 0.997 & 0.045 \\
\hline \multicolumn{7}{|c|}{ halogen } \\
\hline 20 & 0.998 & 0.033 & 0.998 & 0.013 & 0.994 & 0.023 \\
\hline 5 & 0.986 & 0.059 & 0.979 & 0.023 & 0.989 & 0.076 \\
\hline
\end{tabular}

The adjusted $R^{2}$ higher than 0.970 and the low values of RMSE suggested a good correspondence between the experimental and the predicted data both at 5 and $20 \mathrm{kPa}$ of oxygen. So, the $\beta$-carotene degradation of the aqueous solution was properly described in terms of the sigmoid model, as shown in Figure 2, where, for example, the concentration decrease, the $L^{*}$, and the $a^{*}$ changes during the exposition under the cool white lamp and in the dark are shown.

The modeling of the experimental data made it possible to study the acceleration induced by light exposition with respect to dark storage and the effects of the oxygen partial pressure on the photoxidation of the pigment.

All data (induction time and maximum rate) are shown in Table 3 for the storage at 20 and $5 \mathrm{kPa}$ of oxygen. To quantify the effect of light exposure in the acceleration of the $\beta$-carotene degradation (both in terms of concentration, $L^{*}$, and $a^{*}$ changes) for the same oxygen partial pressure, a ratio between the induction time estimated under illumination $\left(\lambda_{1}\right)$ and that estimated in the dark $\left(\lambda_{\mathrm{d}}\right)$ was calculated and expressed as $\lambda_{\mathrm{l}} /$ $\lambda_{\mathrm{d}}$; the same calculus was performed on the rates values $\left(\mu_{1}\right)$ $\mu_{\mathrm{d}}$ ). The results are shown in Table 4.

At $20 \mathrm{kPa}$ of oxygen (Table 4), for all of the analyzed indexes, the induction times were higher in the dark than under illumination: In fact, the ratios $\left(\lambda_{\mathrm{l}} / \lambda_{\mathrm{d}}\right)$ were always lower than 1. The light exposure accelerated the maximum reaction rates as shown by the ratios $\left(\mu_{1} / \mu_{\mathrm{d}}\right)$, which were all higher than 1 .

The presence of an induction phase is probably due to the antioxidant activity of $\beta$-carotene, which, acting both as a physical quencher and a radical trapping, could be able to protect itself from oxidation for a certain time $(16,31,38)$. The induction time could also be due to the protective effect of the thin coating of the fine droplets that surrounded the $\beta$-carotene solubilized in a vegetable oil. This protective effect was found for microcrystalline cellulose and also for starch used as a supporter of $\beta$-carotene, as described by Goldman et al. (41). Moreover, oxygen is more soluble in nonpolar lipids than in aqueous system (13); for this reason, the low water solubility of oxygen could also induce a slack in the photoxidation. The fact that the induction times were always longer and the maximum reaction rates lower in the dark than under illumination might be explained by the different mechanisms involved in the $\beta$-carotene degradation. In fact, in the dark, the oxidation of $\beta$-carotene does not follow a photodegradative route (with the production of singlet oxygen) but a radical pathway that can be induced by temperature (equal to $33{ }^{\circ} \mathrm{C}$ in this experiment) (42) and radical starters (metals or probably other
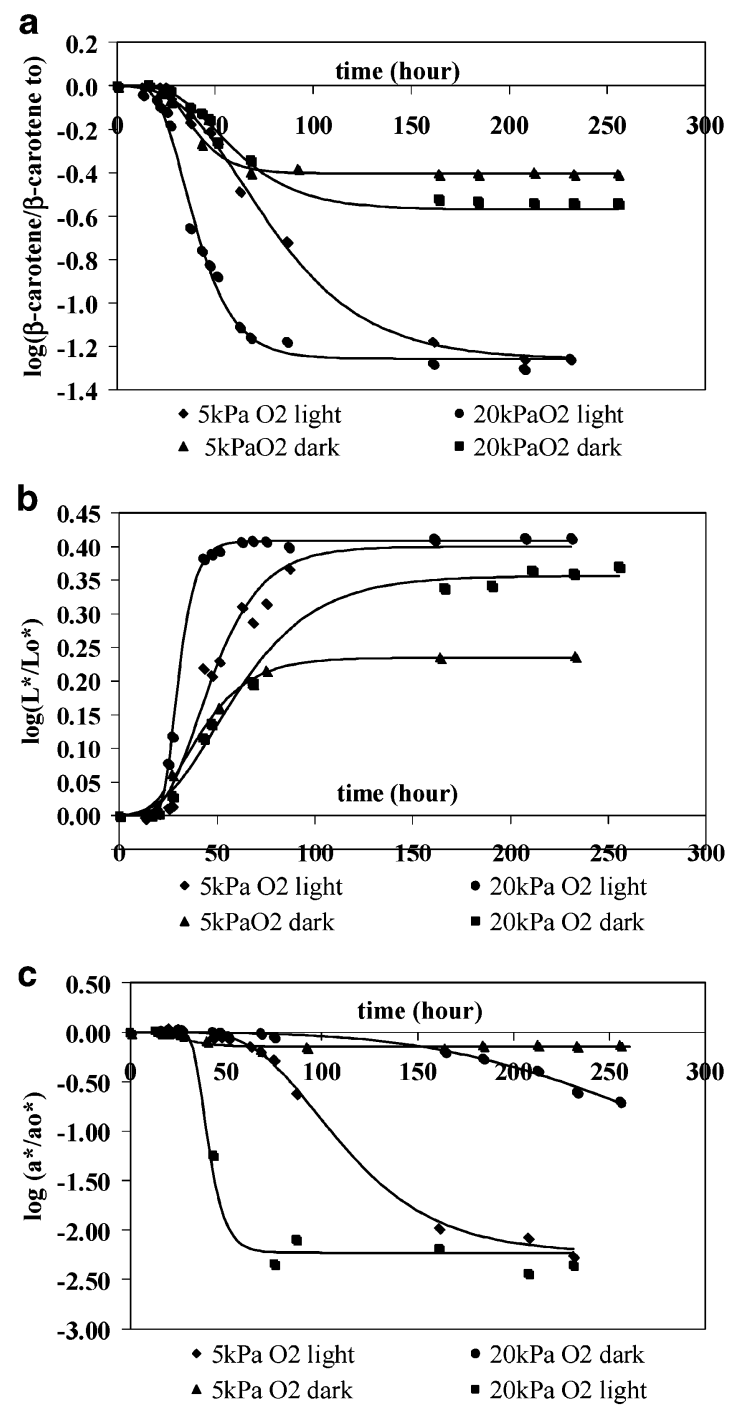

Figure 2. $\beta$-Carotene concentration $(\mathbf{a}), L^{*}(\mathbf{b})$, and $a^{*}(\mathbf{c})$ data for the cool white and dark storage, modeled with the modified Gompertz equation.

contaminants present in water or in the powder). Instead, in lighted conditions, it can suppose that two parallel reactions take place: One is a radical oxidation, and the other is a photoxidation that follows prevalently a type II pathway, where the excited triplet sensitizer may react with the triplet oxygen to form singlet oxygen and singlet sensitize (13). Generally, the rate of singlet oxidation is much greater than that of atmospheric triplet (therefore, radicalic) oxidation (13), explaining the obtained data.

The comparison among the effects of the different lamps was more evident considering the maximal rates values than the induction times. In fact, the length of the induction times was not dependent on the lighting conditions while the rates were influenced by the illuminance and UVA irradiance data measured during the storage experiment (Tables 1 and 3). In other words, the highest rates of changes were found for the cool white lamp, while the lowest rates were found for the halogen lamp.

It was interesting to note that the highest degradation rates were found under illumination with the two lamps less different in terms of illuminance and UVA irradiance. To better investigate these results, the relative spectral distribution of the energy was acquired using an optical probe connected to a detector simulating the real illumination geometry of the cabinets. 
Table 3. Induction Times $(\lambda)$ and Maximum Reaction Rates $(\mu)$ under Lighting and in Darkness at 20 and $5 \mathrm{kPa}$ of Oxygen ${ }^{2}$

\begin{tabular}{|c|c|c|c|c|c|c|c|c|}
\hline $\begin{array}{l}\text { lamp } \\
\text { typology }\end{array}$ & $\mathrm{h}$ & $\begin{array}{c}\beta \text {-carotene } \\
\text { concn }\end{array}$ & $L^{*}$ & $a^{*}$ & $h^{-1}$ & $\begin{array}{c}\beta \text {-carotene } \\
\text { concn }\end{array}$ & $L^{*}$ & $a^{*}$ \\
\hline $\begin{array}{l}\text { cool white } \\
\text { warm white } \\
\text { halogen } \\
\text { dark }\end{array}$ & $\begin{array}{l}\lambda_{1} \\
\lambda_{1} \\
\lambda_{1} \\
\lambda_{d}\end{array}$ & $\begin{array}{r}20.89 \mathrm{c} \\
7.80 \mathrm{a} \\
18.20 \mathrm{~b} \\
26.00 \mathrm{~d}\end{array}$ & $\begin{array}{r}22.30 \mathrm{c} \\
2.50 \mathrm{a} \\
7.44 \mathrm{~b} \\
24.80 \mathrm{~d}\end{array}$ & $\begin{array}{r}20 \mathrm{kPa} \\
20.05 \mathrm{a} \\
30.41 \mathrm{~b} \\
44.12 \mathrm{c} \\
148.00 \mathrm{~d}\end{array}$ & $\begin{array}{l}\mu_{1} \\
\mu_{l} \\
\mu_{1} \\
\mu_{\mathrm{d}}\end{array}$ & $\begin{array}{l}0.0355 \mathrm{~d} \\
0.0264 \mathrm{c} \\
0.0209 \mathrm{~b} \\
0.0091 \mathrm{a}\end{array}$ & $\begin{array}{l}0.0196 \mathrm{~d} \\
0.0137 \mathrm{c} \\
0.0088 \mathrm{~b} \\
0.0049 \mathrm{a}\end{array}$ & $\begin{array}{l}0.1000 d \\
0.0696 c \\
0.0416 b \\
0.0080 a\end{array}$ \\
\hline $\begin{array}{l}\text { cool white } \\
\text { warm white } \\
\text { halogen } \\
\text { dark }\end{array}$ & $\begin{array}{l}\lambda_{1} \\
\lambda_{1} \\
\lambda_{1} \\
\lambda_{d}\end{array}$ & $\begin{array}{l}31.00 c \\
14.30 a \\
12.00 a \\
23.78 b\end{array}$ & $\begin{array}{r}23.10 \mathrm{c} \\
3.30 \mathrm{a} \\
3.30 \mathrm{a} \\
16.50 \mathrm{~b}\end{array}$ & $\begin{array}{c}5 \mathrm{kPa} \\
63.10 \mathrm{~b} \\
69.34 \mathrm{c} \\
173.02 \mathrm{~d} \\
13.60 \mathrm{a}\end{array}$ & $\begin{array}{l}\mu_{1} \\
\mu_{l} \\
\mu_{l} \\
\mu_{\mathrm{d}}\end{array}$ & $\begin{array}{l}0.0136 b \\
0.0123 b \\
0.0095 a \\
0.0135 b\end{array}$ & $\begin{array}{l}0.0076 \mathrm{c} \\
0.0046 \mathrm{ab} \\
0.0040 \mathrm{a} \\
0.0050 \mathrm{~b}\end{array}$ & $\begin{array}{l}0.0701 \mathrm{c} \\
0.0180 \mathrm{~b} \\
0.0055 \mathrm{a} \\
0.0050 \mathrm{a}\end{array}$ \\
\hline
\end{tabular}

${ }^{a}$ For each column, different letters indicate statistically different groups $(p<0.05)$.

Table 4. Ratios of Induction Times $(\lambda)$ and Maximum Reaction Rates $(\mu)$ under Lighting and Dark

\begin{tabular}{|c|c|c|c|c|c|c|c|c|}
\hline $\begin{array}{c}\text { lamp } \\
\text { typology }\end{array}$ & ratio & $\begin{array}{l}\beta \text {-carotene } \\
\text { concn }\end{array}$ & $L^{*}$ & $a^{*}$ & ratio & $\begin{array}{l}\beta \text {-carotene } \\
\text { concn }\end{array}$ & $L^{*}$ & $a^{*}$ \\
\hline $\begin{array}{l}\text { cool white } \\
\text { warm white } \\
\text { halogen }\end{array}$ & $\begin{array}{l}\lambda_{1} / \lambda_{d}{ }^{a} \\
\lambda_{1} / \lambda_{d} \\
\lambda_{1} / \lambda_{d}\end{array}$ & $\begin{array}{l}0.80 \pm 0.02 \\
0.30 \pm 0.05 \\
0.70 \pm 0.02\end{array}$ & $\begin{array}{l}0.90 \pm 0.05 \\
0.10 \pm 0.02 \\
0.30 \pm 0.06\end{array}$ & $\begin{array}{c}20 \mathrm{kPa} \\
0.13 \pm 0.06 \\
0.20 \pm 0.04 \\
0.30 \pm 0.07\end{array}$ & $\begin{array}{l}\mu / \mu_{\mathrm{d}}^{b} \\
\mu \mid \mu_{\mathrm{d}} \\
\mu \mid \mu_{\mathrm{d}}\end{array}$ & $\begin{array}{l}3.90 \pm 0.04 \\
2.90 \pm 0.03 \\
2.30 \pm 0.04\end{array}$ & $\begin{array}{l}4.00 \pm 0.02 \\
2.80 \pm 0.09 \\
1.80 \pm 0.07\end{array}$ & $\begin{array}{r}12.50 \pm 0.12 \\
8.70 \pm 0.15 \\
5.20 \pm 0.09\end{array}$ \\
\hline $\begin{array}{l}\text { cool white } \\
\text { warm white } \\
\text { halogen }\end{array}$ & $\begin{array}{l}\lambda_{1} / \lambda_{d}{ }^{1} \\
\lambda_{1} / \lambda_{d} \\
\lambda_{\mid} / \lambda_{d}\end{array}$ & $\begin{array}{l}1.30 \pm 0.12 \\
0.60 \pm 0.48 \\
0.50 \pm 0.09\end{array}$ & $\begin{array}{l}1.40 \pm 0.06 \\
0.20 \pm 0.45 \\
0.20 \pm 0.08\end{array}$ & $\begin{array}{c}5 \mathrm{kPa} \\
4.60 \pm 0.85 \\
5.10 \pm 0.32 \\
12.70 \pm 0.14\end{array}$ & $\begin{array}{l}\mu / \mu_{\mathrm{d}}^{2} \\
\mu \mid \mu_{\mathrm{d}} \\
\mu \nu / \mu_{\mathrm{d}}\end{array}$ & $\begin{array}{l}1.00 \pm 0.12 \\
0.91 \pm 0.12 \\
0.85 \pm 0.18\end{array}$ & $\begin{array}{l}1.10 \pm 0.05 \\
0.92 \pm 0.17 \\
0.81 \pm 0.14\end{array}$ & $\begin{array}{l}4.00 \pm 0.92 \\
3.60 \pm 0.98 \\
1.10 \pm 0.98\end{array}$ \\
\hline
\end{tabular}

${ }^{a}$ Ratio between the induction time estimated under light $\left(\lambda_{1}\right)$ and in the dark $\left(\lambda_{\mathrm{d}}\right) .{ }^{b}$ Ratio between the rate estimated under light $\left(\mu_{\mathrm{l}}\right)$ and in the dark $\left(\mu_{\mathrm{d}}\right)$.

The difference between the two lamps is well-highlighted in Figure 3, which shows the ratio between the two relative spectra. The cool white had a higher emission in the blue region of the spectrum where the $\beta$-carotene absorbs. This might explain, together with the illuminance and UVA irradiance values, the highest modifications of the aqueous solution exposed under the cool white lamp.

At $5 \mathrm{kPa}$ of oxygen (Table 3), the interpretation of induction times as a function of the storage condition was not simple, as also found at $20 \mathrm{kPa}$. In particular, for the warm white and halogen lamps, the induction times of the $\beta$-carotene concentration and $L^{*}$ curves were shorter than in the dark (i.e., the ratios were lower than 1 as shown in Table 4), meaning that the illumination accelerated the start of oxidation. On the contrary, this situation was not verified during the exposition of the model system under the cool white lamp, and the induction times for the carotenoid concentration and $L^{*}$ were higher than in the dark (ratio higher than 1 ). The ratios of the maximum reaction rates for $\beta$-carotene and $L^{*}$ indexes with respect to the dark $\left(\mu_{1} / \mu_{\mathrm{d}}\right)$ were quite close to 1 , suggesting that the radical reactions seemed to prevail both under light and under dark. In lighted samples, the availability of low oxygen combined with the low water solubility of singlet oxygen could have favored the type I pathway of the photoxidation, where the excited triplet sensitizers that were formed after the absorption of visible and ultraviolet radiation energy acted as a photochemically activated free radical initiator for a radical compound and reacted with the triplet oxygen to form peroxy radical. Generally, as the oxygen in a system becomes depleted, the type I mechanism is favored (13).

In the case of the redness/greenness parameter $\left(a^{*}\right)$ at $5 \mathrm{kPa}$ of oxygen, both the induction and the rate ratios were higher than 1 for all of the selected lamps (Table 4): This means that the modifications described by this component of the color were detected more rapidly in the dark but the rates of reactions were
Table 5. Times at Which Correspond the Maximum and Minimum of the Second Derivative of $\beta$-Carotene, $L^{*}$, and $a^{*}$ Curves $^{a}$ at $5 \mathrm{kPa}$ of Oxygen and Values Achieved at the Stationary Phase $(A)$

\begin{tabular}{|c|c|c|c|c|c|}
\hline \multicolumn{2}{|c|}{$\beta$-carotene concn } & \multicolumn{2}{|c|}{$L^{*}$} & \multicolumn{2}{|c|}{$a^{*}$} \\
\hline $\begin{array}{c}\max \\
d^{2} y / d f^{2}(h)\end{array}$ & $A$ & $\min _{d^{2} y / d f^{2}(h)}$ & $A$ & $\begin{array}{c}\max \\
d^{2} y / d f^{2}(h)\end{array}$ & $A$ \\
\hline \multicolumn{6}{|c|}{ dark } \\
\hline $50 a$ & $0.40 \mathrm{a}$ & $51 \mathrm{a}$ & $0.23 a$ & $70 a$ & $0.14 \mathrm{a}$ \\
\hline \multicolumn{6}{|c|}{ cool white } \\
\hline $97 b$ & $1.26 b$ & $54 \mathrm{~b}$ & $0.39 \mathrm{~b}$ & $112 b$ & $2.93 \mathrm{c}$ \\
\hline \multicolumn{6}{|c|}{ warm white } \\
\hline $98 \mathrm{~b}$ & $1.26 \mathrm{~b}$ & $56 \mathrm{~b}$ & $0.40 \mathrm{~b}$ & $122 \mathrm{~b}$ & $2.24 \mathrm{c}$ \\
\hline \multicolumn{6}{|c|}{ halogen } \\
\hline $189 c$ & $1.42 \mathrm{c}$ & $81 \mathrm{c}$ & $0.39 b$ & $209 c$ & $1.00 \mathrm{~b}$ \\
\hline
\end{tabular}
$0.05)$.

${ }^{a}$ For each column, different letters indicate statistically different groups $(p<$

higher during lighting. This situation can be explained assuming that at low oxygen partial pressures the effect of light and temperature could be limited to causing cis-trans isomerization (36), which probably did not significantly modify the red components of the solution for the time corresponding to the induction phase.

From these data, it might seem that exposition to light did not have a great effect at $5 \mathrm{kPa}$ of oxygen, while the limiting factor was represented by the oxygen. However, considering the maximum of the second derivative of the $\beta$-carotene concentration and $a^{*}$ curves or the minimum of $L^{*}$ curves, it was possible to check when the reaction rates decreased drastically, that is, when the reaction reached the asymptotic level (Table 5). It was evident that the reaction tended to exhaust more rapidly in the dark but without the complete degradation of the reactant, as the values of the increase (or decrease) in $\log C / C_{0}$ between time 0 and the maximum or 


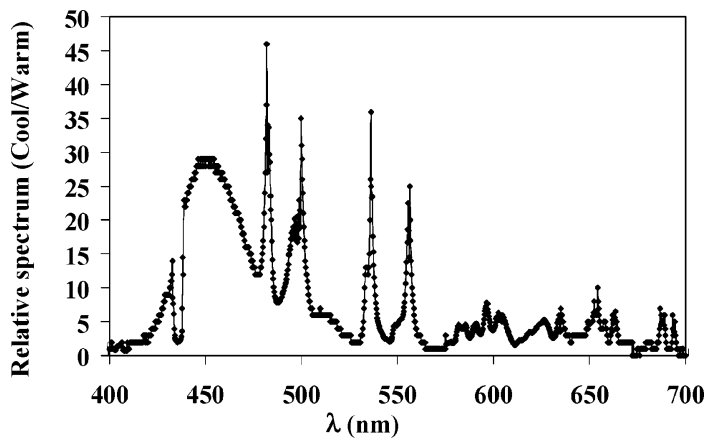

Figure 3. Ratio between the relative emission spectrum of cool and warm white lamps.

minimum value achieved at the stationary phase (parameter A in eq 1) show.

Another consideration may be done; the degradation of the $\beta$-carotene expressed as the decrease in concentration was also described by the lightness changes $\left(L^{*}\right)$, as demonstrated by the similar rate ratios at both 5 and $20 \mathrm{kPa}$ (Table 4).

Comparing the results in the darkness, the maximum rate of $\beta$-carotene degradation at $5 \mathrm{kPa}$ was about 1.5 times higher than that measured at $20 \mathrm{kPa}$ (Table 3). Moreover, also, the induction times were longer at 20 than at $5 \mathrm{kPa}$ of oxygen for all of the analyzed indexes. This behavior could be explained assuming that neighboring $\mathrm{O}_{2}$ molecules, when in liquid form, have a negative exchange energy and thus tend to align antiparallel with each other. So, at high concentrations, this fact could have reduced, for a certain time, the amount of oxygen able to interact with the fine microemulsion structure of the water dispersible $\beta$-carotene. In fact, in a previous work, Goldman and al. (41) found that the presence of oxygen in the headspace (without light exposure) was a crucial factor in $\beta$-carotene degradation but the limiting factor in the oxidation of the dispersed pigment was the adsorbed oxygen content.

During storage, the formation of a volatile compound was also investigated. In fact, the oxidation of carotenoids generally involves epoxidation, the formation of apocarotenoids, and hydroxylation. Subsequent fragmentations result in a series of compounds of low molecular masses and volatiles in nature. In the case of $\beta$-carotene, compounds such as $\beta$-ionone, $\beta$-cyclocitrale, damascenone, and dihydroactinidiolide are considered as degradative volatile products $(43,44)$, which contribute to the aroma/flavor, desirable in tea and wine (45) but undesirable in other foods such as dehydrated carrot and some soft drinks (46). The formation of volatile compounds by thermal degradation of the carotenoids during heat treatment of vegetables products has been mentioned by some authors $(18,19)$. On the contrary, the effects of light and oxygen have been studied probably to a lesser extent, and no references were found.

Figure 4 shows the evolution of $\beta$-ionone, at 20 and $5 \mathrm{kPa}$ of oxygen, during storage under the illumination of the three selected lamps. It is noted that at 5 and $20 \mathrm{kPa}$ of oxygen the trend was the same for all of the storage conditions tested: The $\beta$-ionone level (expressed as area unit) rose up to a maximum and then decreased in time (Figure $\mathbf{4 a}, \mathbf{b}$ ). It was also evident that the maximum of $\beta$-ionone accumulation was reached later in darkness conditions than under light, and in the former case, the amounts accumulated were always lower (Figure 4c). In particular, this phenomena was more noticeable at $5 \mathrm{kPa}$ of oxygen than at $20 \mathrm{kPa}$.

It was expected that higher oxidation rates of $\beta$-carotene would result in the major formation of $\beta$-ionone, but this compound accumulated at lower levels in those samples exposed
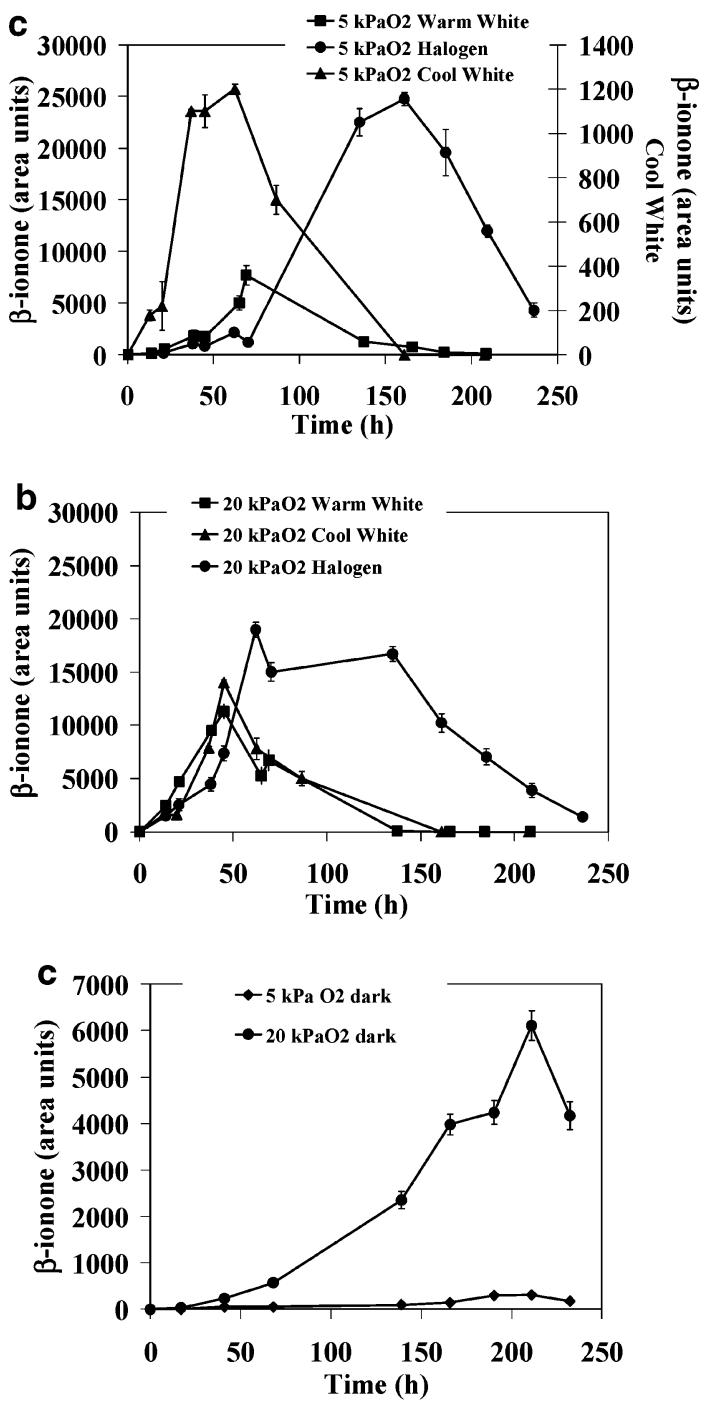

Figure 4. Evolution of $\beta$-ionone during exposition under the three lamps at 20 (a) and $5 \mathrm{kPa}$ (b) and in darkness (c).

to the fluorescent lamps. Both at 5 and $20 \mathrm{kPa}$ of oxygen, the halogen lamp, which gave the lowest rates of degradation in terms of $\beta$-carotene concentration and lightness changes, induced the highest $\beta$-ionone accumulation, especially at $5 \mathrm{kPa}$ of oxygen. This was probably due to the minor $\beta$-ionone degradation during the exposition under this light. In fact, as other authors have sustained $(18,47)$ in a highly reactive environment (like this one where light and oxygen were present), rapid isomerization and oxidation of the degradative products were observed. An arbitrary mathematical model (a peak function) was applied to describe the evolution of $\beta$-ionone to calculate the first and the second time derivatives from which it was possible to estimate the time related to the maximum rate and the acceleration of the volatile production phenomenon. At $20 \mathrm{kPa}$, the time of maximum acceleration of the production of $\beta$-ionone coincided with the induction time calculated from the fitting of the redness/greenness experimental data. In fact, when the redness/greenness index started to decrease, the rate of the $\beta$-ionone production tended to increase. At $5 \mathrm{kPa}$, the maximum of the $\beta$-ionone curves coincided with the estimated induction time for $a^{*}$ curves (Table 6). In other words, this color index $\left(a^{*}\right)$ was able to describe the $\beta$-carotene degradation giving information about the transit of the reaction from the nonvolatile (and colored) to volatile (and colorless) compounds. 
Table 6. Times at Which Correspond the Maximum of the First and Second Derivative of the $\beta$-Ionone Curves ${ }^{a}$

\begin{tabular}{lccccc}
\hline & \multicolumn{2}{c}{$20 \mathrm{kPa} \mathrm{O}_{2}$} & & \multicolumn{2}{c}{$5 \mathrm{kPa} \mathrm{O}_{2}$} \\
\cline { 2 - 3 } \cline { 5 - 6 } $\begin{array}{c}\text { lamp } \\
\text { typology }\end{array}$ & $\begin{array}{c}\max \mathrm{d}^{2} \mathrm{y} / \mathrm{d} \mathrm{d}^{2} \\
\beta \text {-ionone }(\mathrm{h})\end{array}$ & $\begin{array}{c}\text { induction } \\
\text { time } \mathrm{a}^{*}(\mathrm{~h})\end{array}$ & & $\begin{array}{c}\text { max dy/dt } \\
\beta \text {-ionone }(\mathrm{h})\end{array}$ & $\begin{array}{c}\text { induction } \\
\text { time } \mathrm{a}^{*}(\mathrm{~h})\end{array}$ \\
\hline cool white & $21.0 \mathrm{a}$ & $20.0 \mathrm{a}$ & & $62.1 \mathrm{a}$ & $63.1 \mathrm{a}$ \\
warm white & $32.4 \mathrm{~b}$ & $30.4 \mathrm{~b}$ & & $69.0 \mathrm{a}$ & $69.3 \mathrm{a}$ \\
halogen & $43.2 \mathrm{C}$ & $44.1 \mathrm{C}$ & & $175.9 \mathrm{~b}$ & $173.0 \mathrm{~b}$
\end{tabular}

${ }^{a}$ For each column, different letters indicate statistically different groups $(p<0.05)$.

In conclusion, the aqueous solution of $\beta$-carotene had the advantage of simplicity for testing the effects of both light exposure and oxygen partial pressure. The modeling of the experimental data made it possible to estimate the rate of decay of some quality indexes, such as the $\beta$-carotene concentration and the color of the solution. Nevertheless, the kinetic model of aqueous $\beta$-carotene as affected by light, oxygen, and other factors needs further study, and the approach of a multiresponse analysis could allow one to obtain a more realistic kinetic model and thus a deeper insight in reaction mechanisms. In this study, it appeared that lightness index $\left(L^{*}\right)$ seemed to be a good indicator of the decrease in $\beta$-carotene concentration, while the changes in redness/greenness index $\left(a^{*}\right)$ coincided with the production of the volatile compound $\beta$-ionone. This means that the colorimetric measurement is able to describe the molecular changes of $\beta$-carotene during oxidation.

Lighting was also a critical variable in the presence of a low oxygen partial pressure. In fact, even if more slowly than at 20 $\mathrm{kPa}$ of $\mathrm{O}_{2}$, the $\beta$-carotene degraded during storage. The halogen lamp had minor degrading effects on the $\beta$-carotene solution but allowed the highest accumulation of $\beta$-ionone: If this result were verified in a real food system, their use should be recommended for the lighting of products rich in carotenoids but not sensitive to sensorial modifications. The knowledge of the emission spectra of the light sources contributed to explaining the different decay rates of the fluorescent lamps that resulted higher using the cool white light.

From a technological point of view, the packaging materials performances and the modified atmosphere technique need to be optimized to reduce the oxygen content in photosensitive foods. On the other hand, the light sources in the retail stores have to be chosen with care and not just on the basis of cost, efficiency, durability, and aesthetic factors.

\section{LITERATURE CITED}

(1) Barbut, S. Effect of retail lights on acceptability of salami. Meat Sci. 2003, 66, 219-223.

(2) Krawczyk, T. Retail oil packaging. Inform 2000, 11, 932-942.

(3) Thron, M.; Eichner, K.; Ziegleder, G. The influence of light of different wavelenghts on chlorophyll-containing foods. Lebensm.Wiss. Tecnol. 2001, 34, 542-548.

(4) Juric, M.; Bertelsen, G.; Mortensen, G.; Petersen, M. A. Lightinduced colour and aroma changes in sliced, modified atmosphere packaged semi-hard cheeses. Int. Dairy J. 2003, 13, 239249.

(5) Mortensen, G.; Bertelsen, G.; Mortensen, B. K.; Stapelfeldt, H. Light-induced changes in packaged cheeses-A review. Int. Dairy J. 2004, 14, 85-102.

(6) Bosset, J. O.; Gallmann, P. U.; Sieber, R. Influence of light transmittance of packaging materials on the shelf-life of milk and dairy products-A review. In Food Packaging and Preservation; Mathlouthi, M., Ed.; Blackie Academic \& Professional: London, United Kingdom, 1992; pp 222-265.
(7) Parker, C. A. Photoluminescence of Solutions; Elsevier: Amsterdam, The Netherlands, 1968.

(8) Bekbölet, M. Light effects on food. J. Food Prot. 1990, 53, 430440.

(9) Brown, W. E. In Plastic in Food Packaging; Hughes, H. A., Ed.; Marcel Dekker: New York City, New York, 1992; Chapter 1, pp $1-40$

(10) Liu, M. H.; Chen, B. H. Relationship between chlorophyll a and $\beta$-carotene in a lipid-containing model system during heating. Food Chem. 1998, 61, 41-47.

(11) Kalua, C. M.; Bedgood, D. R.; Bishop, A. G.; Prenzler, P. D. Discrimination of storage conditions and freshness in virgin olive oil. J. Agric. Food Chem. 2006, 54, 7144-7151.

(12) Andersen, C. M.; Vishart, M.; Holm, V. K. Application of fluorescence spectroscopy in the evaluation of light-induced oxidation in cheese. J. Agric. Food Chem. 2005, 53, 99859992.

(13) Min, D. B.; Boff, J. M. Chemistry and reaction of singlet oxygen in foods. Comp. Rev. Food Sci. Food Saf. 2002, 1, 58-72.

(14) Lennersten, M.; Lingnert, H. Influence of different packaging materials on lipid oxidation in potato crisps exposed to fluorescent light. Lebensm.-Wiss. Tecnol. 1998, 31, 162-168.

(15) Haisman, D. R.; Groenendijk, C. B. M.; O’Sullivan, G. J. The effect of light on flavour and nutritional content of milk. Paperboard vs. plastic containers. Food Technol. N. Z. 1992, 27 , 16-20.

(16) Henry, L. K.; Pupistari-Nienaber, N. L.; Jarèn-Galàn, M.; Van Breemen, R. B.; Catignani, G. L. Effect of ozone and oxygen on the degradation of carotenoids in an aqueous model system. J. Agric. Food Chem. 2000, 48, 5008-5013.

(17) Jung, M. Y.; Lee, K. H.; Kim, S. Y. Riboflavin-sensitized photochemical changes in $\beta$-lactoglobulin in an aqueous buffer solution as affected by ascorbic acid. J. Agric. Food Chem. 2000, $48,3847-3850$.

(18) Kanasawud, P.; Crouzet, J. C. Mechanism of formation of volatile compounds by thermal degradation of carotenoids in aqueous medium. 1. $\beta$-carotene degradation. J. Agric. Food Chem. 1990, $38,237-243$.

(19) Kanasawud, P.; Crouzet, J. C. Mechanism of formation of volatile compounds by thermal degradation of carotenoids in aqueous medium. 2. Lycopene degradation. J. Agric. Food Chem. 1990, $38,1236-1242$

(20) Moller, J. K. S.; Nannerup, L.; Skibsted, L. H. Effect of carbon dioxide on autoxidation and photooxidation of nitrosylmyoglobin. Meat Sci. 2005, 69, 71-78.

(21) Lennersten, M.; Lingnert, H. Influence of wavelength and packaging material on lipid oxidation and colour changes in lowfat mayonnaise. Lebensm.-Wiss. Tecnol. 2000, 33, 253-260.

(22) Hansen, E.; Skibsted, L. H. Light-induced oxidative changes in a model dairy spread. Wavelength dependence of quantum yields. J. Agric. Food Chem. 2000, 48, 3090-3094.

(23) Jespersen, L.; Strømdahl, L. D.; Olsen, K.; Skibsted, L. H. Heat and light stability of three natural blue colorants for use in confectionery and beverages. Eur. Food Res. Technol. 2005, 220, 261-266.

(24) Hiesberger, J.; Luf, W. Oxidation of cholesterol in butter during storage-Effects of light and storage. Eur. Food Res. Technol. 2000, 211, 161-164.

(25) Lin, C. H.; Chen, B. H. Stability of carotenoids in tomato juice during storage. Food Chem. 2005, 90, 837-846.

(26) Chen, B. H.; Huang, J. H. Degradation and isomerization of chlorophyll a and $\beta$-carotene as affected by various heating and illumination treatments. Food Chem. 1998, 62, 299-307.

(27) Taherian, A. R.; Fustier, P.; Ramaswamy, H. S. Effect of added oil and modified starch on rheological properties, droplet size distribution, opacity and stability of beverage cloud emulsions. J. Food Eng. 2006, 77, 687-696.

(28) Dlużewska, E.; Panasiewicz, M.; Leszczyński. Effect of gum Arabic and modified starch on stability of beverage emulsions. Electr. J. Pol. Agric. Univ. Food Sci. Technol. 2004, www. ejpau.media.pl/volume7/issue2/food/art-10.html. 
(29) Torri, L.; Limbo, S.; Piergiovanni, L. Indagine sulle condizioni di illuminazione dei prodotti alimentari nei punti vendita della grande distribuzione organizzata. Ind. Aliment. 2007, in press.

(30) Everett, S. A.; Dennis, M. F.; Patel, S.; Maddix, S. C.; Kundu, R. L.; Willson, J. Scavenging of nitrogen dioxide, thiyl, and sulfonyl free radicals by the nutritional antioxidant $\beta$-carotene. J. Biol. Chem. 1996, 271, 3988-3994.

(31) Woodall, A. A.; Wai-Ming Lee, S.; Weesie, R. J.; Jackson, M. J.; Britton, G. Oxidation of carotenoids by free radicals: Relationship between structure and reactivity. Biochim. Biophys. Acta 1997, 1336, 33-42.

(32) Jarén-Galàn, M.; Mìnguez-Mosquera, M. I. $\beta$-carotene and capsanthin co-oxidation by lipoxygenase. Kinetic and thermodynamic aspects of the reaction. J. Agric. Food Chem. 1997, 45, 4814-4820.

(33) Gao, G.; Deng, Y.; Kispert, L. D. Photoactivated ferric chloride oxidation of carotenoids by near-UV to visible light. J. Phys. Chem. B 1997, 101, 7844-7849.

(34) Manso, M. C.; Oliveira, F. A. R.; Oliveira, J. C.; Frias, J. M. Modelling ascorbic acid thermal degradation and browning in orange juice under aerobic conditions. Int. J. Food Sci. Technol. 2001, 36, 303-312.

(35) Sakai, Y.; Watanabe, H.; Takai, R. A kinetic model for oxidation of ascorbic acid and beta-carotene. J. Food Process. Preserv. 1987, 11, 197-207.

(36) Kebede, E.; Mannheim, C. H.; Miltz, J. Ascorbic acid retention in a model food packed in barrier plastic trays and cans. Lebensm.-Wiss. Technol. 1998, 31, 33-37.

(37) Chen, S. L.; Gutmanis, F. Auto-oxidation of extractable color pigments in chili pepper with special reference to ethoxyquin treatment. J. Food Sci. 1968, 33, 274-280.

(38) Kim, Y. S.; Strand, E.; Kickmann, R.; Warthesen, J. Degradation of vitamin A palmitate in corn flakes during storage. J. Food Sci. 2000, 65, 1216-1219.
(39) Zwietering, M. H.; de Koos, J. T.; Hasenack, B. E.; van't Riet, K. Modelling of the bacterial growth curve. Appl. Environ. Microbiol. 1990, 56, 1875-1881.

(40) Buzrul, S.; Alpas, H. Modeling the synergistic effect of high pressure and heat on inactivation of Listeria innocua: A preliminary study. FEMS Microbiol. Lett. 2004, 238, 29-36.

(41) Goldman, M.; Horev, B.; Saguy, I. Decolorization of $\beta$-carotene in model systems simulating dehydrated foods. Mechanism and kinetic principles. J. Food Sci. 1983, 48, 751-754.

(42) Martin, H. D.; Ruck, C.; Schnidt, M.; Sell, S.; Beutner, S.; Mayer, B.; Walsh, R. Chemistry of carotenoid oxidation and free radical reactions. Pure Appl. Chem. 1999, 12, 2253-2262.

(43) Lewinshon, E.; Sitrit, Y.; Bar, E.; Azulay, Y.; Meir, A.; Zamir, D.; Tadmor, Y. Carotenoid pigmentation affects the volatile composition of tomato and watermelon fruits, as revealed by comparative genetic analyses. J. Agric. Food Chem. 2005, 53, $3142-3148$

(44) Waché, Y.; Bosser-DeRatuld, A.; Lhuguenot, J. C.; Belin, J. M. Effect of cis/trans isomerism of $\beta$-carotene on the ratios of volatile compounds produced during oxidative degradation. $J$. Agric. Food Chem. 2003, 51, 1984-1987.

(45) Ravichandran, R. Carotenoid composition, distribution and degradation to flavour volatiles during black tea manufacture and the effect of carotenoid supplementation on tea quality and aroma. Food Chem. 2002, 78, 23-28.

(46) Rodriguez-Amaya, D. B. Changes in carotenoids during processing and storage of foods. Arch. Latinoam. Nutr. 1999, 49 (3 Suppl. 1), 38S-47S.

(47) Mordi, R. C.; Walton, J. C. Oxidative degradation of $\beta$-carotene and $\beta$-apo-8'-carotenal. Tetrahedron 1993, 49, 911-928.

Received for review November 27, 2006. Revised manuscript received April 3, 2007. Accepted April 5, 2007.

JF0634348 